\title{
Time course of pulmonary artery pressure during sleep in sleep apnoea syndrome: role of recurrent apnoeas
}

\author{
E. Sforza*, L. Laks, R.R. Grunstein ${ }^{+}$, J. Krieger*, C.E. Sullivan ${ }^{+}$
}

Time course of pulmonary artery pressure during sleep in sleep apnoea syndrome: role of recurrent apnoeas. E. Sforza, L. Laks, R.R. Grunstein, J. Krieger, C.E. Sullivan. CERS Journals Ltd 1998.

ABSTRACT: Recent results in animals have suggested that repetition of hypoxaemic stimuli may result in a progressive increase in pulmonary arterial pressure $(P$ pa $)$. The purpose of the present study was to investigate the effects of recurrent obstructive apnoeas on $P$ pa.

We have, therefore, examined the nocturnal trend of $P_{p a}$ in seven obstructive sleep apnoea syndrome (OSAS) patients and in five snorers. Mean $P$ pa was measured before, at the start, at the end and after the selected apnoeas. The analysis was performed for each $1 \mathrm{~h}$ period for at least $7 \mathrm{~h}$ throughout the night on at least 10 randomly selected apnoeas per hour. In snorers, 100 randomly chosen values were measured during every hour of the night. In the morning after the nocturnal study, the $P$ pa responses to acute hypoxia and hypercapnia were measured.

No $P$ pa changes throughout the $7 \mathrm{~h}$ were found during sleep in snorers $(P$ pa slope:-0.002 $\left.\pm 0.10 \mathrm{mmHg} \cdot \mathbf{h}^{-1}\right)$. In OSAS patients a small but significant increase in $P$ pa throughout the night was noted, affecting the values before $(P$ pa slope: $0.7 \pm 0.16 \mathrm{~mm}$ $\left.\mathrm{Hg} \cdot \mathrm{h}^{-1}\right)$, at the start of apnoea $\left.\left(P \text { pa slope: } 0.53 \pm 0.1 \mathrm{mmHg}^{-1}\right)^{-1}\right)$ as well as at the end $(P$ pa slope: $\left.0.44 \pm 0.08 \mathrm{mmHg}^{-1}\right)$ and in the postapnoeic period $(P$ pa slope: $0.55 \pm 0.1$ mmHg $\cdot h^{-1}$ ). When we limited the analysis to nonrapid eye movement (NREM) sleep, a trend in progressive $P_{\text {pa }}$ was also present, irrespective of changes in apnoea duration and apnoea desaturation. The $P$ pa rise during the night was not affected by diurnal $P$ pa pulmonary vascular response to hypoxia and hypercapnia or indices of sleep apnoea severity.

We conclude that in obstructive sleep apnoea, pulmonary artery pressure progressively increases during the night, reflecting the cumulative effects of apnoeas and nocturnal hypoxaemia.

Eur Respir J 1998; 11: 440-446.
*Sleep Unit, Hopitaux Universitaires de Strasbourg, Strasbourg, France. +Sleep Disorder Centre, Royal Prince Alfred Hospital, Sydney, Australia.

Correspondence: E. Sforza

Clinique Neurologique

Hopitaux Universitaires de Strasbourg

Strasbourg

F-67091 Strasbourg

France

Fax: 33388116343

Keywords: Hypoxaemia pulmonary artery pressure sleep apnoea

Received: January 291997 Accepted after revision October 121997
The increase in pulmonary arterial pressure $(P$ pa $)$ during acute hypoxia is mainly related to alveolar hypoxaemia inducing vasoconstriction of precapillary pulmonary arterioles $[1,2]$ whereas during chronic hypoxia, mechanical and hormonal factors make the vessels adapt to hypoxia and modify their response to chemical stimulus [3]. Furthermore, the temporal profile of the hypoxaemic stimulus may have a substantial effect on the pulmonary vascular response [4] as suggested by experimental studies allowing that repeated exposure to intermittent hypoxaemia [5] enhances the pulmonary hypoxic pressor response.

Previous studies [6] in obstructive sleep apnoea (OSAS) patients have shown that repeated desaturations from obstructive apnoeas induce a transient increase in $P$ pa that, together with daytime hypoxaemia, is considered to be the key factor responsible for daytime pulmonary hypertension [7, 8]. Recent evidence in animals [9-11] has demonstrated that repetitive hypoxic stimuli, simulating the chemical changes produced by apnoeas lead to systemic hypertension either during the exposure or during the recovery period. A more direct approach to the pulmonary vascular effects of repetitive hypoxaemia has been used by
IWASE et al. [12]. Using a canine model they have demonstrated a progressive increase in systemic and pulmonary arterial pressure during repetitive hypoxaemic exposure. On the basis of these latter findings a trend in the pulmonary arterial pressure response to repetitive hypoxaemia similar to the one produced experimentally may occur in patients with OSAS.

The two aims of the present study were: 1) to ascertain whether recurrent apnoea-related oxygen desaturations are associated with a progressive rise in $P$ pa during the night in OSAS patients; 2) if there was a rise in the expected direction, to determine whether diurnal and nocturnal variables would predict the degree of progressive nocturnal increase in $P$ pa.

\section{Patients and methods}

\section{Patients}

Thirty five consecutive patients referred to the sleep laboratory for habitual snoring and possible sleep apnoea 
syndrome were enrolled in the study. All patients underwent pulmonary artery catheterization and nocturnal monitoring of $P$ pa. Patients were eligible if they met the following criteria: 1) at least one rapid eye movement (REM) sleep period during the nocturnal study; 2) no technical problems occurring during the nocturnal monitoring; and 3) no history of heart failure and lung disease. Twelve studies were suitable for analysis.

None of the patients was treated previously with nasal continuous positive airway pressure (nCPAP) or uvulopalatopharyngoplasty and no patient was using vasoactive medication at the time of the study. Written informed consent was obtained from all subjects before they participated in the study, which was approved by the Ethics Committee of the University of Sydney.

Of the 12 patients, seven were defined as OSAS patients having an apnoea+hypopnoea index $(\mathrm{AHI})>10$. The other patients, classified as snorers and with an AHI index $<10$, were considered as the control group.

\section{Methods}

Daytime studies. All subjects underwent a full clinical evaluation including spirometry and arterial blood gases analysis. Lung volumes were measured using the closed circuit helium dilution technique (Morgan, Chatham, Kent, UK) and arterial blood gases were measured by an automatically calibrated $178 \mathrm{pH} / \mathrm{blood}$ gas analyser (Ciba Corning Medfield, MA, USA).

The pulmonary artery catheterization was performed at rest, breathing room air with the patients in a semirecumbent position. A single lumen, 4F pulmonary microcatheter (Pulmoflex, Vygon, Germany) was introduced into the pulmonary artery via the right or left cubital vein, under the control of distally obtained pressure curves recorded continuously on a HP 78353B pressure monitor (HewlettPackard, USA) and a Mingograph 400/700 System (Siemens, Stockholm, Sweden) recorder. After calibrating the recorder, using a mercury manometer, $P$ pa was recorded with the transducer placed $5 \mathrm{~cm}$ below the sternal angle manubriosternal joint. After 15 min of rest, the mean values for systolic and diastolic $P$ pa were obtained, averaging the values of at least five respiratory cycles. Mean pulmonary arterial pressure $\left(\bar{P}_{\mathrm{pa}}\right)$ was calculated following the reported equation: $\bar{P}_{\mathrm{pa}}=($ mean systolic pressure $+2 \times$ mean diastolic pressure)/3. A $\bar{P}_{\text {pa value }}$ S $20 \mathrm{mmHg}$ was defined as pulmonary hypertension. The catheter was then left in situ for overnight recording of pulmonary artery pressure.

In the morning after the nocturnal study, $P$ pa response to hypoxia and hypercapnia was measured according to the previously described protocol [13]. Ventilatory response tests were performed with the subject sitting upright breathing via a mouth piece using a modified version of the methods described by ReAD [14] and ReBucK and CAmpbell [15]. The rebreathing circuit included a flow- through bag, a variable bypass soda-lime absorber and a fixed speed blower. The bag was encased in a perspex box connected to a pneumotachograph allowing measurements of tidal volume $(V \mathrm{~T})$. End-tidal partial pressure of carbon dioxide $\left(P\right.$ et, $\left.\mathrm{CO}_{2}\right)$ was kept constant by varying flow through the soda-lime absorber and by adding $\mathrm{CO}_{2}$ to the circuit. $P$ et, $\mathrm{CO}_{2}$ was measured at the mask using an infrared analyser (47210 capnometer; Hewlett Packard, USA).
Airflow, oxygen saturation and $\bar{P}_{\text {pa }}$ were measured on a breath-by-breath basis throughout the test period and recorded on a polygraph. Tidal volume was calculated by integrating the flow signal. In the eucapnic hypoxic condition the $P$ et, $\mathrm{CO}_{2}$ was kept constant at resting values and hypoxia was produced by stopping oxygen supply and by a controlled administration of $100 \%$ nitrogen into the circuit. The ramp of hypoxia was terminated at an arterial oxygen saturation $\left(\mathrm{Sa}_{\mathrm{a}} \mathrm{O}_{2}\right)$ of $70 \%$ within $2-3$ min of starting the test. Normoxic hypercapnic rebreathing runs were performed using a mixture of $\mathrm{CO}_{2}$ and the test was terminated when the $P$ et, $\mathrm{CO}_{2}$ reached a level of $>10 \mathrm{mmHg}(1.3$ $\mathrm{kPa})$ above the mixed venous plateau. $\mathrm{Sa}, \mathrm{O}_{2}$ remained $>97 \%$ throughout the test.

Two hypoxic and hypercapnic tests were performed, separated by a recovery period of $15 \mathrm{~min}$, and the $P$ pa response was obtained in duplicate and averaged. The regression of $\bar{P}_{\mathrm{pa}}$ on $\mathrm{Sa}_{\mathrm{a}} \mathrm{O}_{2}$ and $P$ et, $\mathrm{CO}_{2}$ were calculated for each patient and the value obtained per percentage change (ý) in $\mathrm{Sa}_{\mathrm{a}} \mathrm{O}_{2}$ (mean ý $\mathrm{Pa} / \hat{y} \mathrm{Sa}_{2} \mathrm{O}_{2}$, in $\mathrm{mmHg} \cdot \%^{-1}$ ) and per unit partial pressure of $\mathrm{CO}_{2}$ (mean ý $P$ pa/ý $P$ et, $\mathrm{CO}_{2}$, in $\mathrm{mmHg} \cdot \mathrm{mm}$ $\left.\mathrm{Hg}^{-1}\right)$ was used to express the $P$ pa responsiveness to a given change in oxygen saturation and $P$ et, $\mathrm{CO}_{2}$.

\section{Nocturnal studies}

Protocol. Each patient was studied on a single night for at least $7 \mathrm{~h}$ between 22:30 h and 06:00 h. Polysomnography included electroencephalogram (EEG), electro-oculogram (EOG), submental and diaphragm electromyogram (EMG) and electrocardiogram (ECG). Nasal and oral airflow was recorded by a thermistor. Respiratory movements were monitored by strain gauge transducers placed around the chest and the abdomen (Ambulatory Monitoring Inc., Ardsley, NY system). Arterial oxyhaemoglobin saturation was continuously measured by an ear oximeter (Biox III, Ohmeda). $P$ pa was recorded through a single lumen, $4 \mathrm{~F}$ pulmonary microcatheter inserted in an antecubital vein and connected to a calibrated pressure transducer. Prior to the recording, a calibration of the system was performed using a mercury manometer. This manoeuvre was repeated each hour during the nocturnal study to verify the stability of the recorded pressure. All signals were continuously recorded on a polygraph (model 78D, Grass Instruments, Quincy, MA) at a paper speed of $10 \mathrm{~mm} \cdot \mathrm{s}^{-1}$.

Sleep stages were scored using the method of ReCHTSCHAFFEN and KaLES [16]. Central, mixed and obstructive apnoeas were defined according to standard criteria. Hypopnoeas were defined by an estimated $50 \%$ or greater reduction in oronasal flow with a decrease in $\mathrm{Sa}_{\mathrm{a}} \mathrm{O}_{2}$ of at least 4\%. The apnoea index (AI; number of apnoeas per hour of sleep), AHI (number of apnoeas and hypopnoeas per hour of sleep), the apnoea time (percentage of total sleep time spent in apnoea) and the mean duration of respiratory events were computed. The following indices of hypoxaemia were defined: the mean $\mathrm{Sa}_{\mathrm{a}} \mathrm{O}_{2}$ during $10 \mathrm{~min}$ of quiet wakefulness prior to sleep onset $\left(\mathrm{Sa}_{\mathrm{a}} \mathrm{O}_{2}, \mathrm{w}\right)$; the low $\mathrm{Sa}_{\mathrm{a}} \mathrm{O}_{2}$ (mean minimal $\mathrm{Sa}, \mathrm{O}_{2}$ after each event); the AHI at $\mathrm{Sa}_{\mathrm{a}} \mathrm{O}_{2}<90 \%$ (number of apnoeas and hypopnoeas per hour of sleep with a low $\mathrm{Sa}_{\mathrm{a}} \mathrm{O}_{2}$ below $90 \%$ ), and the AHI at $\mathrm{Sa}_{2} \mathrm{O}_{2}$ $<80 \%$ (number of apnoeas and hypopnoeas per hour of sleep with a low $\mathrm{Sa}_{2} \mathrm{O}_{2}$ below $80 \%$ ). Oximeter values below $40 \%$ were considered to be equal to $40 \%$ because of the alinearity of the instrument in this range. 


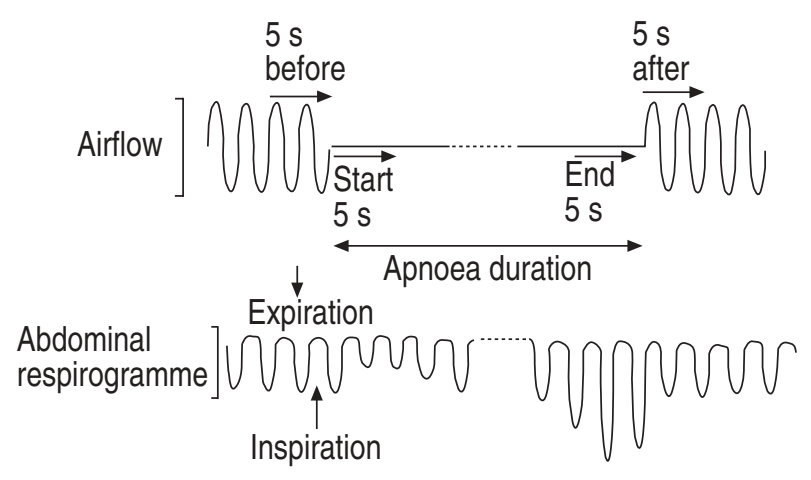

Fig. 1. - Schematic representation of the analysis.

\section{Data analysis}

Analysis was performed for periods of $1 \mathrm{~h}$ from light off to light on for at least $7 \mathrm{~h}$. For each period, the AHI, the AHI at $\mathrm{Sa}_{\mathrm{a}} \mathrm{O}_{2}<90 \%$, the AHI at $\mathrm{Sa}_{\mathrm{a}} \mathrm{O}_{2}<80 \%$, the low $\mathrm{Sa}_{\mathrm{a}} \mathrm{O}_{2}$ and the mean duration of apnoeas were calculated.

During $10 \mathrm{~min}$ of relaxed wakefulness prior to sleep onset ( $P$ pa presleep) and for the selected apnoeas during each $1 \mathrm{~h}$ period, $P$ pa was analysed manually, computing the mean value of systolic and diastolic pressure $(P$ pa,mean: mean systolic $P$ pa + mean diastolic $P$ pa/2). This was done for the pressure recorded during the expiratory phase, defined by the analysis of diaphragm EMG activity, to exclude the effects of negative intrathoracic pressure swings during the obstructive efforts.

For each OSAS patient, at least 10 obstructive apnoeas were randomly selected for each $1 \mathrm{~h}$ period occurring either in nonrapid eye movement (NREM) and REM sleep, in supine position. Apnoeas with arrhythmia or artefacts related to body movements were rejected from the analysis. Apnoeas lasting $10 \mathrm{~s}$, occurring while the patients were falling asleep and preceded or followed by body movements, were discarded. The duration of the selected apnoeas was equal to the mean duration for the entire night \pm 1 SD. For each selected apnoea (fig. 1), the $P$ pa average was considered in four segments: $P$ pa during the $5 \mathrm{~s}$ before an apnoea ( $P$ pa,before); $P$ pa during the first $5 \mathrm{~s}$ at the start of the apnoea $(P \mathrm{pa}$, start $) ; P$ pa during the last $5 \mathrm{~s}$ of apnoea ( $P$ pa,end); and $P$ pa during the first $5 \mathrm{~s}$ of the postapnoeic phase $(P$ pa, after). These periods were determined with all polygraphic data to define as accurately as possible the start and the end of apnoea. No data were analysed twice, i.e. as postapnoea in one episode and as pre-apnoea in the following one.

In the snorers, to compute $P$ pa,mean, at least 100 random values for each $1 \mathrm{~h}$ period were analysed, so that an equivalent number of pressure readings was obtained in snorers and in OSAS patients.

\section{Statistical analysis}

All values are presented as mean \pm SEM. Comparisons between snorers and OSAS patients were made using oneway analysis of variance (ANOVA). Data from periods obtained for each subject were averaged and the slope of $P$ pa variation from the first to the last hour was obtained in all subjects for total sleep and for NREM sleep. Two-way
ANOVA for repeated measurements followed by Scheffé test for multiple comparison was used to test for differences between pre-apnoeic, apnoeic and postapnoeic phases and to test for the effect of the hour of the night. The analysis was performed for the total sleep period and for NREM sleep periods. The relationships between the slope of increase in $P$ pa during the night and diurnal and nocturnal parameters were analysed using Pearson's correlation analysis. Rejection of the null hypothesis required a pvalue of less than 0.05 .

\section{Results}

Table 1 presents demographic, pulmonary and nocturnal parameters for comparison of the OSAS patients and snorers.

OSAS patients had a mean AHI of $83.7 \pm 6.7$; the apnoea time was $43.1 \pm 0.4 \%$ of total sleep time and the mean duration of apnoeas $26.7 \pm 0.8 \mathrm{~s}$. In all subjects a high percentage of obstructive apnoeas were recorded $(78 \%)$, with no central and few mixed apnoeas $(22 \%)$. OSAS patients were characterized by moderate or severe hypoxaemia in sleep with a mean low $\mathrm{Sa}_{\mathrm{a}} \mathrm{O}_{2}$ of $77.5 \pm 0.5 \%$, a mean $\mathrm{AHI}$ at $\mathrm{Sa}, \mathrm{O}_{2}<90 \%$ of $75.1 \pm 0.5$ and a mean $\mathrm{AHI}$ at $\mathrm{Sa}, \mathrm{O}_{2}<80 \%$ of $36.3 \pm 0.4$. In the snorers the mean AHI was $6.8 \pm 1.3$ and the mean low $\mathrm{Sa}_{2} \mathrm{O}_{2} 92.0 \pm 0.8 \%$.

Three OSAS patients had pulmonary hypertension (defined as a $\bar{P}_{\text {pa }} \breve{\mathrm{S}} 20 \mathrm{mmHg} ; 26,26$ and $27 \mathrm{mmHg}$, respectively) while one snorer had a $\bar{P}_{\text {pa }}$ of $21 \mathrm{mmHg}$. None of the OSAS patients showed restrictive or obstructive lung disease or daytime hypoxaemia. Obstructive lung disease defined as a forced expiratory volume in one second (FEV1)/ forced vital capacity (FVC) ð70\% was present in two snorers. Mild hypercapnia, defined as a $\mathrm{Pa}_{\mathrm{a}} \mathrm{CO}_{2} \stackrel{\mathrm{S}}{\mathrm{S}} 45 \mathrm{mmHg}(6.0$ $\mathrm{kPa})$, was present in three OSAS patients $(46,46$ and 51

Table 1. - Clinical and nocturnal respiratory findings in subjects with obstructive sleep apnoea syndrome (OSAS) and snorers

\begin{tabular}{|c|c|c|c|}
\hline & OSAS group & Snorer group & $\mathrm{p}$-value \\
\hline Subjects $n$ & 7 & 5 & \\
\hline Age yrs & $43(3)$ & $42(4)$ & NS \\
\hline $\mathrm{BMI} \mathrm{kg} \cdot \mathrm{m}^{-2}$ & 38.7 (1.6) & $30.2(5.6)$ & 0.01 \\
\hline $\bar{P}$ pa diurnal $\mathrm{mmHg}$ & $22.9(1.3)$ & $15.8(1.5)$ & 0.005 \\
\hline$P$ pa presleep $\mathrm{mmHg}$ & $12.7(0.5)$ & $7.2(0.8)$ & 0.008 \\
\hline$P \mathrm{a}, \mathrm{O}_{2} \quad \mathrm{mmHg}$ & $80.6(3.4)$ & $88.8(3.4)$ & NS \\
\hline${\mathrm{Pa}, \mathrm{CO}_{2}}_{\mathrm{mmHg}}^{\mathrm{mm}}$ & $44.6(1.3)$ & $43.0(1.6)$ & NS \\
\hline FEV1 mL & 2937 (146) & $3320(366)$ & NS \\
\hline FVC mL & 3784 (111) & 4473 (668) & NS \\
\hline $\begin{array}{l}\text { ý } P \text { pa/ý } P \text { et, }, \mathrm{CO}_{2} \\
\text { mmHg } \cdot \mathrm{mmHg}^{-1}\end{array}$ & $0.53(0.09)$ & $0.23(0.04)$ & 0.02 \\
\hline ýPpa/ýSa, $\mathrm{O}_{2} \mathrm{mmHg} \cdot \%^{-1}$ & $0.33(0.05)$ & $0.20(0.03)$ & NS \\
\hline AHI $n \cdot h^{-1}$ & $83.7(6.6)$ & $6.8(1.3)$ & \\
\hline Low $\mathrm{Sa}_{\mathrm{a}} \mathrm{O}_{2} \%$ & $77.5(0.5)$ & $92.0(0.8)$ & 0.002 \\
\hline Apnoea duration $\mathrm{s}$ & $26.7(0.8)$ & $13.8(1.0)$ & 0.005 \\
\hline \multicolumn{4}{|c|}{$\begin{array}{l}\text { Values are presented as mean with SEM in parenthesis. BMI: body } \\
\text { mass index; } \bar{P}_{\mathrm{pa}} \text { diurnal: daytime mean pulmonary artery pres- } \\
\text { sure; AHI: apnoea }+ \text { hypopnoea index; } P \text { pa: pulmonary artery } \\
\text { pressure; } P \mathrm{a}, \mathrm{O}_{2}: \text { arterial oxygen tension; } P_{\mathrm{a}, \mathrm{CO}}: \text { arterial carbon } \\
\text { dioxide tension; FEV } 1 \text { : forced expiratory volume in one second; } \\
\text { FVC: forced vital capacity; ý } P \text { pa/ý } P_{\mathrm{et}}, \mathrm{CO}_{2}: \text { pulmonary artery } \\
\text { pressure response to hypercapnia; ý } P \text { pa/ý } S_{\mathrm{a}, \mathrm{O}_{2}}: \text { pulmonary artery } \\
\text { pressure response to hypoxia. }\end{array}$} \\
\hline
\end{tabular}


$\mathrm{mmHg}(6.1,6.1$ and $6.8 \mathrm{kPa})$ respectively ) and in one snorer $(49 \mathrm{mmHg}(6.5 \mathrm{kPa}))$.

As shown in Table 1, age, blood gas analysis and spirometry were not different between the two groups of subjects whereas body mass index (BMI) and daytime $\bar{P}$ pa were significantly lower in snorers. The slopes of $P$ pa responses to hypoxia and hypercapnia were greater in OSAS patients, but the difference achieved significance only in the hypercapnic response.

The sleep and respiratory parameters for each $1 \mathrm{~h}$ period in OSAS patients are presented in table 2. In the OSAS patients, sleep was disrupted, with lower sleep efficiency (79\%) and higher number of arousals and awakenings. Sleep architecture was characterized by a higher percentage of light sleep (stages 1 and 2: mean 90.8 $1.5 \%$ ), an absence of slow wave sleep and a reduced amount of REM sleep (mean: $9.2 \pm 1.8 \%$ ). REM sleep was recorded in all patients, occurring especially in the second and third hour of sleep and in the second half of the night. The hourly distribution of apnoeas and the apnoea time did not differ significantly throughout the night, whereas more severe fall in $\mathrm{Sa}_{2} \mathrm{O}_{2}$ occurred during the REM sleep periods.

The polygraphic and haemodynamic data for each $1 \mathrm{~h}$ period in OSAS patients and snorers are presented in table 3 . Five hundred and seven apnoeas were analysed in the

Table 2. - Sleep and respiratory parameters for each hour of total sleep in obstructive sleep apnoea syndrome patients

\begin{tabular}{|c|c|c|c|c|c|}
\hline & $\begin{array}{l}\text { NREM } \\
\text { sleep } \\
\text { min }\end{array}$ & $\begin{array}{l}\text { REM } \\
\text { sleep } \\
\text { min }\end{array}$ & $\begin{array}{l}\text { AHI } \\
n \cdot h-1\end{array}$ & $\begin{array}{c}\text { Low } \\
\mathrm{Sa}_{\mathrm{a}, \mathrm{O}_{2}} \\
\%\end{array}$ & $\begin{array}{c}\text { Minimal } \\
\mathrm{Sa}_{\mathrm{a}, \mathrm{O}_{2}} \\
\%\end{array}$ \\
\hline$\overline{\text { Hour } 1}$ & $37.3(5.8)$ & $2.8(1.0)$ & $89.6(8.5)$ & $81.9(1.6)$ & $70.4(2.4)$ \\
\hline Hour 2 & $47.4(5.8)$ & $3.6(2.8)$ & $88.8(8.2)$ & $77.7(3.1)$ & $61.4(6.4)$ \\
\hline Hour 3 & $49.3(5.1)$ & $8.0(4.9)$ & $87.9(5.8)$ & 76.9 (2.2) & $62.9(4.5)$ \\
\hline Hour 4 & $43.1(6.5)$ & $3.2(2.0)$ & $83.0(6.1)$ & 81.8 (1.6) & $68.7(2.3)$ \\
\hline Hour 5 & $48.3(6.6)$ & $5.7(3.1)$ & $82.9(5.6)$ & $78.8(1.2)$ & $58.3(4.2)$ \\
\hline Hour 6 & $41.3(5.8)$ & 6.9 (3.9) & $86.2(6.3)$ & 77.3 (1.6) & $60.3(5.8)$ \\
\hline Hour 7 & 36.7 (6.9) & $6.7(3.8)$ & $85.1(6.3)$ & $76.5(1.3)$ & $55.3(5.4)$ \\
\hline
\end{tabular}

Values are presented as mean with SEM in parenthesis. NREM: nonrapid eye movement; REM: rapid eye movement; AHI: apnoea + hypopnoea index; $\mathrm{S}_{\mathrm{a}, \mathrm{O}_{2}}$ : arterial oxygen saturation; Low $S_{\mathrm{a}, \mathrm{O}_{2}}$ : mean minimal $\mathrm{Sa}_{\mathrm{a}} \mathrm{O}_{2}$ after each event.
OSAS patients with a mean duration of $28.5 \pm 0.2 \mathrm{~s}$ and a mean low $\mathrm{Sa}_{\mathrm{a}} \mathrm{O}_{2}$ of $76.2 \pm 0.2 \%$. All apnoeas included in the analysis were obstructive and their mean duration did not differ from the overall value during the night. During obstructive apnoeas, $P$ pa increased significantly across the apnoea, until a maximum was reached in the postapnoeic period $(\mathrm{F}=29.6, \mathrm{p}=0.001)$. Compared with presleep values of $12.7 \pm 0.5 \mathrm{mmHg}$, as the night progressed (table 2), there was a small cumulative increase in $P$ pa $(\mathrm{F}=7.8$; $\mathrm{p}=0.001$ ). Figure 2 illustrates the average $P$ pa values of each segment of apnoea against the hours of night for the total sleep period in each patient and in each control. Inspection of the figure reveals that the pattern of $P$ pa rise in OSAS pat-ients is similar before, during and after the apnoea. The mean slope of $P$ pa increase during sleep was $0.7 \pm 0.2 \mathrm{~mm} \mathrm{Hg} \cdot \mathrm{h}^{-1}$ for $P$ ap,before (range $0.2-1.6 \mathrm{mmHg} \cdot \mathrm{h}$ 1), $0.53 \pm 0.1 \mathrm{mmHg} \cdot \mathrm{h}^{-1}$ for $P$ pa,start $\left(0.2-1.0 \mathrm{mmHg} \cdot \mathrm{h}^{-1}\right)$, $0.44 \pm 0.1 \mathrm{mmHg} \cdot \mathrm{h}^{-1}$ for $P$ pa,end $\left(0.2-0.8 \mathrm{mmHg} \cdot \mathrm{h}^{-1}\right)$ and $0.55 \pm 0.1 \mathrm{mmHg} \cdot \mathrm{h}^{-1}$ for $P$ pa,after $\left(0.2-0.8 \mathrm{mmHg} \cdot \mathrm{h}^{-1}\right)$. As shown in figure 2 , the rise was greater in some patients compar-ed to the others and in some hours of the night. This in-crease was significantly different $(p=0.001)$ from the slope obtained in snorers. In snorers, no significant changes in $P$ pa average value occurred during the night $(P$ pa slope $\quad-0.002 \pm 0.03 \mathrm{mmHg}$, range $-0.6-0.1$ ). $P$ pa was $10.0 \pm 1.0 \mathrm{mmHg}$ in the first hour and $10.1 \pm 1.1$ $\mathrm{mmHg}$ in the last hour, with no significant changes compared to presleep values.

To exclude the confounding effects of REM sleep on apnoea duration and apnoea desaturation, the statistical analysis was also performed considering only NREM sleep periods (table 4). As the night progressed, $P$ pa increased significantly from the first to the last hour of the night. The mean change throughout the night was: $0.63 \pm 0.19$ $\mathrm{mm} \mathrm{Hg} \cdot \mathrm{h}-1$ (F=8.9, $\mathrm{p}<0.001)$ for $P$ pa,before; $0.47 \pm 0.11 \mathrm{~mm}$ $\mathrm{Hg} \cdot \mathrm{h}^{-1}(\mathrm{~F}=9.1 . \mathrm{p}<0.001)$ for $P$ pa,start; $0.39 \pm 0.10 \mathrm{mmHg} \cdot \mathrm{h}^{-1}$ $(\mathrm{F}=4.0, \mathrm{p}=0.003)$ for $P \mathrm{pa}$,end; and $0.45 \pm 0.10 \mathrm{mmHg} \cdot \mathrm{h}^{-1}$ $(\mathrm{F}=5.7, \mathrm{p}=<0.001)$ for $P$ pa,after. There were no consistent changes in the apnoea duration or mean low $\mathrm{Sa}_{\mathrm{a}} \mathrm{O}_{2}$ for the analysed apnoeas from the first to the seventh hour of sleep.

A Pearson's correlation analysis including, diurnal $\bar{P}_{\mathrm{pa}}$ $P \mathrm{a}, \mathrm{O}_{2}, P \mathrm{a}, \mathrm{CO}_{2}, \mathrm{AHI}$, mean low $\mathrm{Sa}_{2} \mathrm{O}_{2}$, apnoea duration and apnoea time, and the slope of $P$ pa,before, $P$ pa,start, $\mathrm{Ppa}$,end

Table 3. - Duration, oxygen desaturation and pulmonary artery pressure ( $\left.\bar{P}_{\mathrm{pa}}\right)$ values of the selected apnoeas for each hour of total sleep in obstructive sleep apnoea syndrome (OSAS) patients. For snorers, Ppa for every hour of sleep is represented

\begin{tabular}{|c|c|c|c|c|c|c|c|c|}
\hline & \multicolumn{7}{|c|}{ OSAS patients } & \multirow{2}{*}{$\begin{array}{c}\text { Snorers } \\
P_{\text {pa }} \\
\mathrm{mmHg}\end{array}$} \\
\hline & $\begin{array}{c}\text { Apnoea } \\
n\end{array}$ & $\begin{array}{l}\text { Apnoea } \\
\text { duration } \\
\mathrm{s}\end{array}$ & $\begin{array}{c}\text { Low } \\
\mathrm{S}_{\mathrm{a}, \mathrm{O}_{2}} \\
\%\end{array}$ & $\begin{array}{c}P \text { pa,before } \\
\text { mmHg }\end{array}$ & $\begin{array}{l}P \text { pa,start } \\
\text { mmHg }\end{array}$ & $\begin{array}{l}P \text { pa,end } \\
\mathrm{mmHg}\end{array}$ & $\begin{array}{l}P \text { pa,after } \\
\text { mmHg }\end{array}$ & \\
\hline Hour 1 & 70 & $26.1(0.3)$ & $78.2(0.4)$ & $15.6(0.6)$ & $13.7(0.6)$ & $16.3(0.8)$ & $18.1(1.1)$ & $10.0(1.0)$ \\
\hline Hour 2 & 70 & $27.8(0.5)$ & $74.8(0.7)$ & $17.4(0.7)$ & $15.5(0.5)$ & $18.1(0.8)$ & $20.0(1.0)$ & $10.4(1.1)$ \\
\hline Hour 3 & 74 & $28.8(0.5)$ & $75.6(0.5)$ & 19.1 (1.1) & $16.5(0.8)$ & $18.6(0.9)$ & $21.1(1.2)$ & $9.8(1.0)$ \\
\hline Hour 4 & 68 & $26.6(0.4)$ & $81.0(0.4)$ & $17.3(0.7)$ & $15.5(0.8)$ & $17.6(1.3)$ & $19.5(1.3)$ & 10.0 \\
\hline Hour 5 & 74 & $29.1(0.6)$ & $75.9(0.6)$ & $19.1(1.2)$ & $17.3(0.9)$ & $19.5(0.7)$ & $21.9(1.0)$ & 10.0 \\
\hline Hour 6 & 75 & $30.5(0.6)$ & $73.3(0.7)$ & $20.6(1.3)$ & $17.7(0.9)$ & $19.9(1.1)$ & $22.6(1.5)$ & $10.1(1.2)$ \\
\hline Hour 7 & 76 & $30.6(0.7)$ & $73.7(0.6)$ & $19.7(1.2)$ & $16.9(0.7)$ & $19.0(1.0)$ & $21.3(1.2)$ & $10.1(1.1)$ \\
\hline
\end{tabular}

The analysis included both rapid eye movement (REM) and nonREM sleep periods. Low $S_{a}, \mathrm{O}_{2}$ : mean minimal arterial oxygen saturation after each event; $P$ pa,before: pulmonary artery pressure $(P$ pa $)$ during the $5 \mathrm{~s}$ before an apnoea; $P$ pa,start: $P$ pa during the first $5 \mathrm{~s}$ at the start of an apnoea; $P$ pa,end: $P$ pa during the last $5 \mathrm{~s}$ of an apnoea; $P$ pa,after: $P$ pa during the first $5 \mathrm{~s}$ of the postapnoeic phase. 

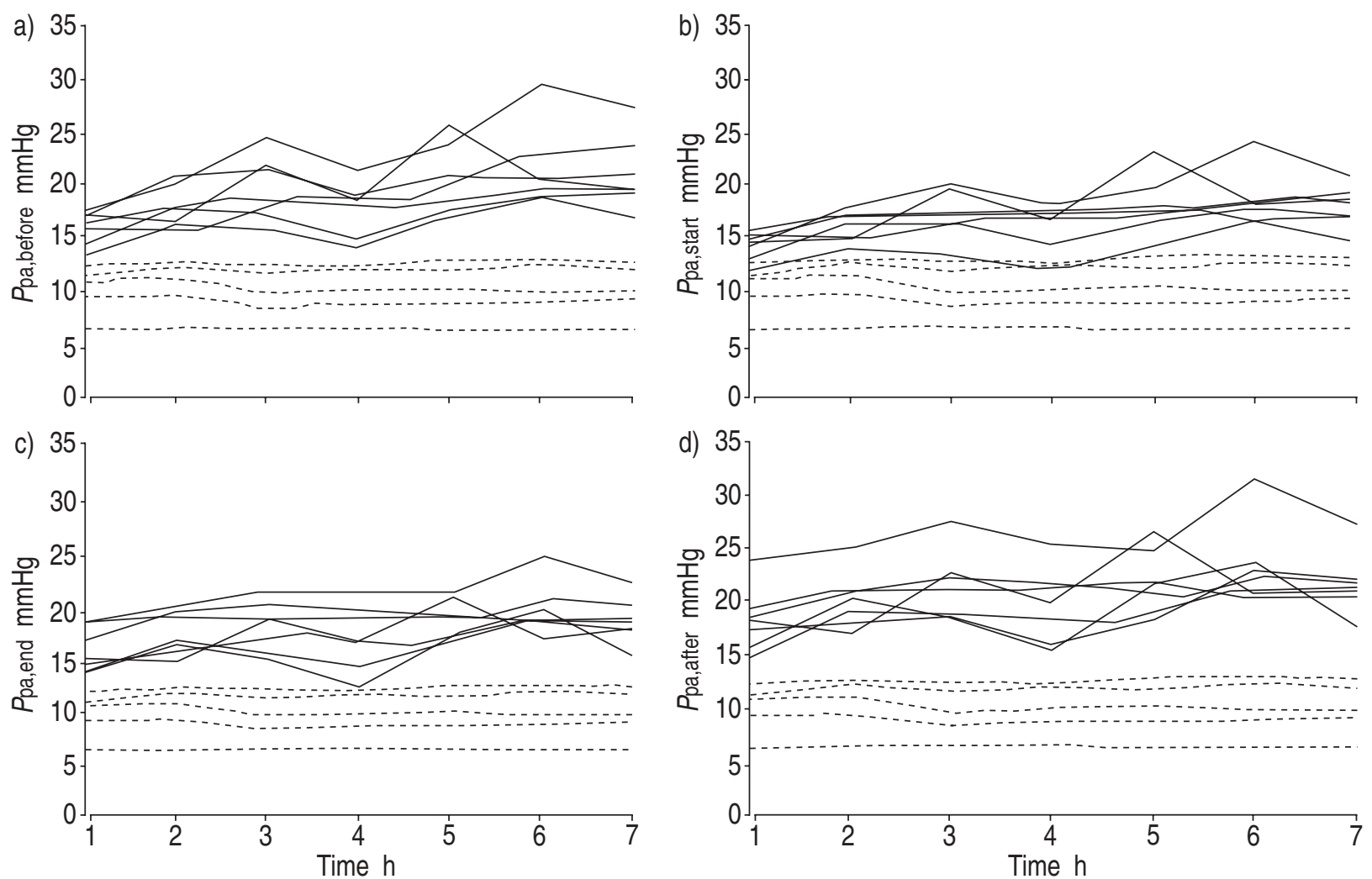

Fig. 2. - The mean $P$ pa values are represented for snorers ( _ _ ) and OSAS patients ( $~-~)$ for 7 h of the night. For OSAS patients, the data are plotted for the $P$ pa before and after the apnoea as well as for $P$ pa at the start and the end of apnoea. Compared to snorers, OSAS patients showed a small but significant increase in $P$ pa from the first to the last hour of the night. For definitions see table 3.

Table 4. - Duration, oxygen desaturation and mean pulmonary artery pressure values for the analysed apnoeas for each hour of nonrapid eye movement (NREM) sleep in obstructive sleep apnoea syndrome (OSAS) patients

\begin{tabular}{lccccccc}
\hline & $\begin{array}{c}\text { Apnoea } \\
\mathrm{n}\end{array}$ & $\begin{array}{c}\text { Apnoea } \\
\text { duration } \\
\mathrm{s}\end{array}$ & $\begin{array}{c}\text { Low } \\
\mathrm{a}_{\mathrm{a}, \mathrm{O}_{2}} \\
\%\end{array}$ & $\begin{array}{c}P \text { pa,before } \\
\mathrm{mmHg}\end{array}$ & $\begin{array}{c}P \text { pa,start } \\
\mathrm{mmHg}\end{array}$ & $\begin{array}{c}P_{\text {pa,end }} \\
\mathrm{mmHg}\end{array}$ & $\begin{array}{c}P \text { pa,after } \\
\mathrm{mmHg}\end{array}$ \\
\hline Hour 1 & 60 & $24.1(0.3)$ & $79.2(0.4)$ & $15.6(0.6)$ & $13.7(0.5)$ & $16.4(0.8)$ & $18.2(1.1)$ \\
Hour 2 & 63 & $26.9(0.4)$ & $77.5(0.5)$ & $16.9(0.6)$ & $14.8(0.7)$ & $17.3(1.0)$ & $19.1(1.2)$ \\
Hour 3 & 64 & $27.2(0.4)$ & $78.4(0.4)$ & $17.9(0.8)$ & $15.6(0.6)$ & $17.8(1.0)$ & $20.0(1.0)$ \\
Hour 4 & 61 & $26.6(0.4)$ & $81.0(0.4)$ & $17.2(0.6)$ & $15.5(0.7)$ & $17.6(1.2)$ & $19.4(1.2)$ \\
Hour 5 & 61 & $27.1(0.4)$ & $80.0(0.3)$ & $18.4(0.6)$ & $16.1(0.7)$ & $18.0(0.9)$ & $20.0(0.9)$ \\
Hour 6 & 62 & $28.1(0.5)$ & $77.6(0.3)$ & $19.8(1.0)$ & $17.1(0.9)$ & $19.1(1.2)$ & $21.2(1.3)$ \\
Hour 7 & 61 & $26.5(0.4)$ & $76.4(0.4)$ & $19.5(1.1)$ & $16.5(0.9)$ & $18.7(1.2)$ & $20.9(1.3)$ \\
\hline
\end{tabular}

Values are presented as mean \pm SEM, from analysis of NREM sleep periods only. For definitions see legend to table 3.

and $P$ pa,after during total sleep and NREM sleep, showed that none of the variables considered were correlated with the slope of $P$ pa increase during the various intervals. Furthermore, no correlations were found between the slope of $P$ pa during the night and the diurnal vascular pulmonary pressure response to hypoxia and hypercapnia.

\section{Discussion}

Using $1 \mathrm{~h}$ analysis of nocturnal $P$ pa, we demonstrated a progressive increase in $P$ pa in OSAS patients. This increase was detectable from the beginning to the end of the night, with a maximal rise prior to awakening. In contrast, there were no significant changes in snorers. This finding suggests that as sleep progressed, the recurrent stimulus of the repetitive apnoeas and hypoxaemia may have contributed to nocturnal pulmonary hypertension.

Studies in OSAS patients have shown that $P$ pa increases are transient and mainly postapnoeic with a return to baseline values when $\mathrm{Sa}_{\mathrm{a}} \mathrm{O}_{2}$ returns to preapnoeic levels [6]. The new finding of this study is that a nocturnal trend of progressive increase in $P$ pa is present in OSAS patients, but not in snorers. This suggests that repetitive episodic hypoxia or stress resulting from the apnoea-related chemical or mechanical changes may amplify pulmonary bed vasoconstriction during the night, contributing to the upward trend found in the present patients.

The potential mechanisms underlying these apnoeadependent changes in $P$ pa were not specifically examined in our study and remain undetermined. However, we know that the adjustment of $P$ pa in response to obstructive 
apnoea results from a complex interplay between several factors including the reactivity of local vascular bed, the hypoxia-related vasoconstriction and possibly the direct influence of the decrease in intrathoracic pressure during the apnoea. It has been demonstrated experimentally [3-5, 12] that pulmonary vascular responsiveness depends on the intensity, the duration and the repetition of the hypoxic stimulus applied. MARRoNe et al. [17] found that transmural systolic $P$ pa progressively increased during repetitive apnoeas in four OSAS patients only when the falls in $\mathrm{Sa}_{\mathrm{a}} \mathrm{O}_{2}$ became greater and in REM sleep. In our analysis, we first included values during NREM and REM sleep so that changes in $P$ pa would reflect the time course during the night. According to previous data, we would assume that the rise in pulmonary pressure is greater during REM sleep and when hypoxaemia is more severe. However, after the elimination of REM sleep periods, an upward trend in $P$ pa was still observed. This result suggests that the repetition of hypoxic stimuli, rather than the intensity of hypoxaemia, may influence the haemodynamic response to obstructive apnoea. In animals [5], the repetition of hypoxaemia induces a temporal pattern of progressive increase in $P$ pa present after the first five or six hypoxic exposures and affecting values during the stimulation as well as during the recovery period. Although the data from the present study suggest that certain indices of nocturnal hypoxaemia, $i$ e. low $\mathrm{Sa}_{\mathrm{a}} \mathrm{O}_{2}$ and minimal $\mathrm{Sa}_{\mathrm{a}} \mathrm{O}_{2}$ are not a sufficient explanation for the rise in $P$ pa, they do not exclude other effects of episodic and repetitive hypoxaemia on nocturnal pulmonary hypertension. Although speculative, the intermittent nature of hypoxaemic stimuli in OSAS may affect the nocturnal $P$ pa rise by modifying the vascular response to chemical stimuli either directly on pulmonary vascular muscles $[18,19]$ or indirectly via vasoactive mediators. Alternatively, anatomical vascular remodelling [20] or pulmonary capillary damage [21], related to recurrent apnoeas, may lead to potentiation of pulmonary vessel reactivity. These intrinsic modifications of the vascular pulmonary bed would elicit major vascular responses to hypoxic stimulus. This hypothesis is supported by experimental data $[5,12]$ showing that application of repetitive hypoxia for several hours is followed by an hyperactivity of the pulmonary vascular bed that persists in the recovery period.

Our approach, however does not exclude the possibility that factors other than hypoxaemia contributed to the rise in $P$ pa. We know that the acute cardiovascular response to apnoea is complicated by the interaction of mechanical effects (i.e. changes in intrathoracic pressures) that may have an effect on pulmonary vasoreactivity, either directly or by the increase in venous return and right ventricular diastolic size. Although a mechanical effect cannot be entirely excluded in the present patients, we believe it is unlikely. In snorers, in whom an increase in negative oesophageal pressure is present, $P$ pa was maintained and no changes were detectable throughout the night. This is in keeping with the results of IwASE et al. [12] showing that during airway obstruction, oxygen inhalation reverses the cyclical changes in $P$ pa, and intermittent hypoxia without obstruction may cause rises in systemic artery pressure and $P$ pa that do not differ in magnitude from those associated with obstruction. These data are consistent with the view that increased mechanical loading during apnoea does not play a key role in mediating the progressive rise in $P$ pa.

It remains unclear from the present data whether the trend of evolution of $P$ pa during the night is affected by the diurnal pulmonary vascular setting. It was previously documented that some subjects are more susceptible (high responders) to the development of pulmonary hypertension in hypoxic conditions than others (nonresponders) [22, 23]. However, in the present study no significant correlations were found between diurnal vascular response to hypoxia and hypercapnia, daytime $\bar{P}$ pa and the slope of $P$ pa changes during the night. It might be noted that diurnal vascular response to hypoxia may not reflect the changes in the pulmonary artery pressure at night. In OSAS patients, MARRONE et al. [24], comparing the change in systolic blood pressure with changes in $\mathrm{Sa}, \mathrm{O}_{2}$ during hypercapnic hypoxia, normocapnic hypoxia and sleep found a greater systemic vascular response during wakefulness than during sleep. LaKs et al. [13] measured the response of $\bar{P}_{\text {pa }}$ to hypoxia and hypercapnia during wakefulness in 20 OSAS patients and nine controls and found a wide range of response to hypoxia in both groups. A potential problem with the interpretation of these results lies in the method of analysis of diurnal pulmonary vascular response to hypoxia. We used a chronic hypoxic stimulus that may not provide an accurate quantitative assessment in the OSAS situation. Therefore, it is conceivable that statistically significant differences in $P$ pa responses to obstructive apnoea might be observed only when comparing the vascular response at a similar level of $\mathrm{Pa}, \mathrm{O}_{2}$ and duration of hypoxic stimulus.

While it is not necessarily possible to extrapolate the present findings to a general OSAS population they do demonstrate the potentially negative effects of obstructive apnoeas during sleep. Controversy surrounds the mechanisms responsible for diurnal pulmonary hypertension. Some authors have stressed the role of diurnal hypoxaemia [25], others have considered the effects of repetition of apnoeas and nocturnal hypoxaemia [26]. Considering the nocturnal trend of progressive rise in $P$ pa found in the present patients it is conceivable that in the long term these patients if left untreated would develop irreversible anatomical vascular changes underlying diurnal pulmonary hypertension. This would be a further incentive to provide early treatment of OSAS to prevent the risk of diurnal pulmonary hypertension.

We have acknowledged, above, some of the limitations of this study that may have affected the results. Firstly, to measure $P$ pa we used intravascular $\bar{P}_{\mathrm{pa}}$, which is directly influenced by the changes in intrathoracic pressure occurring during obstructive apnoeas. Since oesophageal pressure was not recorded, we decided to analyse expiratory values of $P$ pa on the basis that during normal respiration intravascular $\bar{P}_{\text {pa equals transmural }} \bar{P}$ pa only at the end of expiration. If this is correct for the segments before and at the start of apnoea, at the end of apnoea and in the postapnoeic period, a shortening of expiratory time is present, caused by an activation of expiratory muscles. This means that the criteria for intravascular $\bar{P}$ pa being equal to

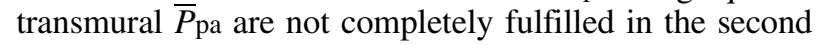
part of apnoea and in the postapnoeic period. For this reason relative changes in $\bar{P}_{\mathrm{pa}}$, more than absolute values, were considered for the statistical analysis. Secondly, since in the present OSAS patients, the nocturnal $P_{\mathrm{pa}}$ rise 
was significant but small, the question arises whether artefacts or body movements may have affected the results. In an attempt to control the variables that may induce variations in our measurements, only supine position was allowed during the study and periods with artefacts or body movements were discarded from the analysis. Moreover, the pressure calibration was rechecked each hour during the nocturnal recording and identical techniques were used in all subjects. Since no changes were observed in snorers, we do not believe that the nocturnal $P$ pa increase found in OSAS patients may be related merely to technical interference in $P$ pa measurement. Finally, several factors such as age, BMI and lung disease may influence $P$ pa independently of OSAS. In the present study the best possible age matching was attempted and patients with a history of lung disease were excluded. Unfortunately we did not succeed in fully matching the study groups for BMI and daytime pulmonary function, both of which may act as potential confounders. However, although the size of the study groups was not large enough to draw a conclusion with certainty, up to now no systematic studies have been performed in order to examine the evolution of $P$ pa during sleep. Coccagna et al. [27] described an increase in $P$ pa that parallels the deepening of sleep from stage 1 to stage 4, the highest values being recorded in REM sleep. Measurements, however, were made randomly during the night and not correlated with the changes in $\mathrm{Sa}_{\mathrm{a}} \mathrm{O}_{2}$ or apnoea dura-tion.

In summary, we observed a progressive rise in nocturnal pulmonary artery pressure during the course of the night in patients with obstructive sleep apnoea syndrome. The specific mechanisms underlying this temporal trend remain to be established. Research efforts should focus on how diurnal or nocturnal factors may differentiate the patients who had the greatest progressive nocturnal rise and the consequence of this rise on the development of diurnal pulmonary hypertension.

\section{References}

1. Von Euler US Liljestrand G. Observation on pulmonary arterial blood pressure in the cat. Acta Physiol Scand 1946; 12: 301-320.

2. Fishman AP. Hypoxia on the pulmonary circulation. Circ Res 1976; 38: 221-231.

3. Cutaia M, Rounds S. Hypoxic pulmonary vasoconstriction. Physiological significance mechanism and clinical relevance. Chest 1990; 97: 706-718.

4. Miller MA, Hales CA. Stability of alveolar vasoconstriction with intermittent hypoxia. J Appl Physiol 1980; 49: 846-850.

5. Unger MM, Atkins M, Briscoe WA, King TK. Potentiation of pulmonary vasoconstrictor response with repeated intermittent hypoxia. J Appl Physiol 1977; 43: 662-667.

6. Podszus T, Mayer J, Penzel T, Peter J, Von Wichert P. Nocturnal hemodynamics in patients with sleep apnea. Eur Respir Dis 1986; 69: 435-442.

7. Bradley TD, Rutheford R, Grossman RF, et al. Role of daytime hypoxemia in the pathogenesis of right heart failure in the obstructive sleep apnea syndrome. Am Rev Respir Dis 1985; 131: 835-839.

8. Krieger J, Sforza E, Apprill M, Lampert E, Weitzenblum E, Ratamaharo J. Pulmonary hypertension hypoxemia and hypercapnia in obstructive sleep apnea patients. Chest 1989; 96: 729-737.

9. Fletcher EC, Lesske CK, Qian W, Miller CC, Unger T.
Repetitive episodic hypoxia causes diurnal elevation of blood pressure in rats. Hypertension 1992; 19: 555-561.

10. Fleteher EC, Lesske J, Behm R, Miller CC III, Stauss H, Unger T. Carotid chemoreceptors, systemic blood pressure and chronic hypoxia mimicking sleep apnea. $J$ Appl Physiol 1992; 72: 1978-1984.

11. Bakehe M, Miramand JL, Chambille B, Gaultier C, Escourrou P. Cardiovascular changes during acute episodic repetitive hypoxic and hypercapnic breathing in rats. Eur Respir J 1995; 8: 1675-1680.

12. Iwase N, Kikuchi Y, Hida W, et al. Effects of repetitive airway obstruction on $\mathrm{O}_{2}$ saturation and systemic and pulmonary arterial pressure in anesthetized dogs. Am Rev Respir Dis 1992; 148: 1402-1410.

13. Laks L, Lehrhaft B, Grunstein RR, Sullivan CE. Pulmonary artery pressure response to hypoxia in sleep apnea. Am J Respir Crit Care Med 1997, 155: 193-198.

14. Read DJC. A clinical method tor assessing the ventilatory response to carbon dioxide. Australas Am Med 1967; 16: 20-32.

15. Rebuck AS, Campbell EJ. A clinical method for assessing the ventilatory response to hypoxia. Am Rev Respir Dis 1973; 109: 345-350.

16. Rechtschaffen A, Kales A. A Manual of Standardized Terminology, Technique and Scoring System for Sleep Stages of Human Sleep. Los Angeles Brain Information Service. Los Angeles, Brain Information Institute, UCLA, 1968.

17. Marrone O, Bonsignore MR, Romano S, Bonsignore G. Slow and fast changes in transmural artery pressure in obstructive sleep apnoea. Eur Respir J 1994; 7: 2192-2198.

18. Kay JM, Suyma KL, Keane PM. Effect of intermittent normoxia on muscularisation of pulmonary arterioles induced by chronic hypoxia in rats. Am Rev Respir Dis 1981; 123: 454-458.

19. Nattie EE, Bartlett D, Johnson K. Pulmonary hypertension and right ventricular hypertrophy caused by intermittent hypoxia and hypercapnia. Am Rev Respir Dis 1978; 118: 653-658.

20. Sajkov D, Cowie RJ, Thornton AT, Espinoza HA, McEvoy RD. Pulmonary hypertension and hypoxemia in obstructive sleep apnea syndrome. Am J Respir Crit Care Med 1994; 149: 416-422.

21. West JB, Mathieu-Costello O. Stress failure of pulmonary capillaries: role in lung and heart disease. Lancet 1992; 340: 769-767.

22. Beard JT, Newmann JH, Lloyd JE, Bird BF. Doppler estimation of changes in pulmonary artery pressure during hypoxic breathing. J Am Soc Echo 1991; 4: 121-130.

23. Will DH, Hicks JL, Card CS, Alexander AF. Inherited susceptibility of cattle to high-altitude pulmonary hypertension. J Appl Physiol 1975; 38: 491-494.

24. Marrone O, Insalaco G, Romano S, Salvaggio A, Bonsignore MR, Bonsignore G. Chemical stimuli and blood pressure during wakefulness and sleep in obstructive sleep apnoea. Eur Respir J 1995; 8: Suppl. 19, 213s.

25. Chaouat A, Weitzenblum E, Krieger J, Oswald M, Kessler R. Pulmonary hemodynamics in the obstructive sleep apnea syndrome: results in 220 consecutive patients. Chest 1996; 109: 380-386.

26. Schroeder JS, Motta J, Guilleminault C. Hemodynamics studies in sleep apnea. In: Guilleminault C, Dement WC, eds. Sleep Apnea Syndrome. New York, Alan Liss, 1978; pp. 177-196.

27. Coccagna G, Mantovani M, Brignani $F$, Parchi C, Lugaresi E. Continuous recording of the pulmonary and systemic arterial pressure during sleep in syndromes of hypersomnia with periodic breathing. Bull Physiolopathol Respir 1972; 8: 1159-1172. 